\title{
The response of firms to eligibility thresholds: Evidence from the Japanese value-added tax
}

\author{
Kazuki Onji \\ Crawford School of Economics and Government, Australian National University, Canberra, ACT0200, Australia
}

\section{A R T I C L E I N F O}

\section{Article history:}

Received 7 December 2006

Received in revised form 14 September 2008

Accepted 22 December 2008

Available online 7 January 2009

\section{Keywords:}

$\mathrm{H} 32$

H25

L22

Tax avoidance

Business group

Value-added tax

Firm size distribution

\begin{abstract}
A B S T R A C T
It is common to define benefit eligibility for small business policies by restrictions on the firm size. This paper documents the effects of the value-added tax (VAT) threshold in Japan, focusing on the incentives for a large firm to "masquerade" as many small firms by separately incorporating business segments. A comparison of the corporate size distributions before and after the VAT introduction of 1989 shows a clustering of corporations just below the threshold-a pattern that is attributable to the behavioral responses. To rule out the confounding influences of the changes in the company attributes over the years, we applied a semiparametric density decomposition technique developed by DiNardo, Fortin, and Lemieux (DiNardo J., Fortin N.M., Lemieux T., Labor market institutions and the distribution of wages, 1973-1992: a semiparametric approach. Econometrica 1996; 64; 1001-1044). This study suggests that the masquerading behavior by firms may be commonplace in other settings.
\end{abstract}

(c) 2008 Elsevier B.V. All rights reserved.

\section{Introduction}

A host of public policies favor small over large firms, and it is common to define benefit eligibility by restrictions on the number of employees or on alternative measures of firm size. ${ }^{1}$ There are often sound rationales for exempting small firms from complying with regulations, including the Americans with Disabilities Act that would otherwise impose disproportionate compliance costs on small businesses, and from filing a tax return, including that for a valueadded tax (VAT) where the costs of administration do not justify the amount of tax collected from small tax payers. Yet the tax and regulatory systems are rendered complex by the preferential treatment by firm size, giving rise to a clear concern about policy-induced distortions in firm behavior. Despite the pervasiveness of policy thresholds, to this author's knowledge, the distortions are discussed in press but not well documented in the academic literature. There have been theoretical studies (Keen and Mintz, 2004; Dixon et al., 2004) and an empirical study (Schivardi and Torrini, 2004) that focused on the disincentives for firms to grow beyond the benefit threshold out of

E-mail address: Kazuki.Onji@anu.edu.au.

${ }^{1}$ For example, the Title I of the Americans with Disability Act prohibits discrimination against persons with disabilities in employment by businesses having 15 or more employees (Acemoglu and Angrist, 2001). In a small business support program in the UK analyzed by Wren and Storey (2002), the eligibility requirement is no more than 500 employees. Under the Emergency Petroleum Allocation Act of 1973, small oil refiners below a set production capacity were not subjected to price controls (Viscusi et al., 2001). Under the 1990 Clean Air Act Amendment, the federal government mandated that states formulate a program applicable to organizations that own or operate more than 10 vehicles in designated areas (Callan and Thomas, 2004). concern for the benefit eligibility. Though such behavior is plausible for stand-alone firms, a firm in practice can have a flexible structure that allows it to respond in diverse ways without placing restriction on its growth. Just as so-called "barrier hopping" in the context of foreign direct investment, where a firm creates a subsidiary in the importing country with a high tariff to bypass the tax, a large firm may avoid the loss of eligibility by creating multiple subsidiaries that are legally independent but have a common ownership and control, subject to the legal provisions against such strategies. ${ }^{2}$ Thus, the literature leaves undocumented a variety of behavioral responses that are potentially relevant in policy making.

The purpose of this paper is to document the behavioral response caused by a tax threshold in the context of the VAT introduction of 1989 in Japan. The tax reform was an overhaul of the Japanese tax system affecting the economy of the nation, but what makes this policy change an attractive "natural experiment" is the sudden appearance of tax incentives. The VAT brought along a preferential tax scheme for small businesses, with eligibility for the scheme at or below 500 million yen in sales. Company-level data on corporate groups available from both before and after the tax reform allow us to ask questions: do firms respond to an eligibility threshold by adjusting organizational structures? Is a tax threshold influential enough to affect the appearance of the size distribution of business entities? What are the efficiency consequences? Although the specificity of the

\footnotetext{
${ }^{2}$ Similarly, after the Second World War, the US banks sought to overcome the restriction on interstate banking by separately chartering banks in different states (Matasar and Heiney, 2002).
} 
setting renders direct generalization to other countries difficult, ${ }^{3}$ a case study on a VAT threshold would be of interest in itself. ${ }^{4}$

An intuitive way to identify the overall influence of a policy threshold would be to examine the size distribution of businesses in the neighborhood of the threshold. This paper implements kernel density estimation and compares the corporate size distributions in 1988 and 1990 using Affiliated Company Data (ACD), an annual survey of publicly-traded companies that collects information on their domestic subsidiaries. ${ }^{5}$ The companies in ACD are affiliates of corporate groups and account for $57.4 \%$ of paid-in capital in the corporate sector in 1988. The average sample size is 14,800 corporations per year. To check whether confounding influences might mask any effects of the tax, we apply the density decomposition technique developed by DiNardo, Fortin and Lemieux (1996), which allows one to control for changes in observable characteristics across the period.

Evidence found in this study is consistent with the hypothesis that a policy threshold induces firms to restructure their organizations by splitting some of their member corporations. The post-reform densities are thicker than the pre-reform densities at and below the threshold. In other words, there is a "bunching" attributable to the presence of pervasive tax avoidance. Furthermore we observe a decline in densities in a range above the threshold. Though we do not strictly distinguish between different types of behavioral responses in this paper, the tax-motivated splitting explain the overall pattern better than some other explanations.

This paper adds to the studies on the effects of taxes on organizational structures in the tax avoidance literature. ${ }^{6}$ Though tax incentives may be apparent to informed observers, including in the case of VAT thresholds, ${ }^{7}$ the relevance to firm decisions is a matter of empirical question. It is difficult to assess the pervasiveness of tax avoidance behavior. But due to the lack of documentation the practical importance of tax incentives is sometimes questioned, as in the textbook example of a multi-stage turnover tax. ${ }^{8}$ This tax in theory creates incentives to merge with upstream suppliers since the tax is levied at each point that goods change possession: Williamson (1985) dismisses the tax incentives as a minor one. ${ }^{9}$ Our study neither refutes nor supports Williamson's position since our focus is not on the boundaries between economically independent organizations but rather on the boundaries between distinct legal entities belonging to a close-knit group. In this regard, our study relates to the literature on business groups ${ }^{10}$ and, in a broad sense, to the study

\footnotetext{
${ }^{3}$ As a method of computing VAT liabilities, most countries adopt the "invoice-credit method". Japan instead adopts the "subtraction method." The benefit of VAT exemption is greater under the subtraction method than under the invoice-credit method. Thus, all else being equal, the Japanese VAT creates a stronger incentive to be under the VAT exemption threshold. See Ebrill et al. (2001, pp. 19-22) for details. The distinction between these methods is, however, not generally relevant in the current context; our analysis is on the simplified filing scheme rather than the VAT exemption.

${ }^{4}$ More than 120 countries have adopted VAT and thresholds are incorporated in the majority of them. As for the OECD nations with a VAT, $84 \%$ adopt a threshold. See Ebrill et al. (2001) for a summary of international institutions.

${ }^{5}$ Kankei Gaisha Data in Japanese. The data is published in print as a directory of Japanese conglomerate, Nihon no Kigyo Gurupu by Toyo Keizai Co. Westney (1998 provides a discussion on corporate groups, sometimes referred to as a "vertical keiretsu" or "capital keiretsu." A distinction should be made from a "horizontal keiretsu," which refers to a group centered on the main bank system (see Flath, 2005).

${ }^{6}$ Goolsbee and Maydew (2002) is similar to this study in focusing on divisive operations. Studies on tax avoidance by firms include income shifting by multinational corporations (Grubert and Mutti, 1991; Hines and Rice, 1994; Grubert and Slemrod, 1998) and the choice of organizational form (Gordon and MacKie-Mason, 1990, 1994, 1997)

${ }^{7}$ Ebrill et al. (2001, p. 121) discuss the case of VAT exemption thresholds. Scholes et al. (2002) consider the effects of taxes on organizational structure in general.

${ }^{8}$ Another example is the effects of taxes on merger and acquisition activities, where the evidence in the literature is mixed (e.g. Scholes and Wolfson, 1990; Auerbach and Reishus, 1988)

${ }^{9}$ See also Pedone (1981).
}

by Stephens and Ward-Batts (2004) on income shifting between husbands and wives. Khanna and Yafeh (2005) argue that the origin of business groups is not well understood; our contribution is to provide evidence on the role of taxes in group formation.

It is of interest to understand the impact of the tax policy on the size distribution of businesses, an important but understudied field. ${ }^{11}$ Industry concentration has been studied extensively (Curry and George, 1983; Schmalensee, 1988, 1989) but, except for the study on mergers by Auerbach and Reishus (1988), the role of taxes has received relatively little attention, even in the subfield that focuses on small firms, where the effects of taxes are likely to be stronger (White, 1982; Baldwin and Gorecki, 1985; Hu, 1999). Since our study considers the effects at the economy level, rather than at the market level, the object of the analysis is similar to that of the firm size distribution literature (Lucas, 1978; Stanley et al., 1995; Hart and Oulton, 1997; Cabral and Mata, 2003; Schivardi and Torrini, 2004). A distinction is that these studies presume that the unit of observation, i.e. a legal entity such as a joint stock corporation, is also the unit of decision making. Our study does not share this premise and recognizes the distinction between a firm and a legal entity. "Masquerading" behavior has a potential bearing on the interpretation of the measure of market concentration. ${ }^{12}$

The paper proceeds as follows. Section 2 summarizes the tax law and discusses the tax incentives. Section 3 considers issues in the implementation of empirical analysis. Technical details are presented in Appendix A. Section 4 presents and discusses the results. Section 5 concludes.

\section{VAT reform and behavioral responses}

\subsection{Simplified filing scheme: basic features}

Against the backdrop of a growing government debt and an aging population, a consumption-type VAT known as "consumption tax" was introduced in Japan in April 1989, replacing commodity taxes that had narrow bases. ${ }^{13}$ Overall, the Japanese VAT had a simple structure: the tax rate was uniform at 3\% and relatively few items were exempted. ${ }^{14}$ However, the treatment of small business was unusually generous by the OECD standard as a result of the political concession given by the leading Liberal Democratic Party (LDP) to its business constituents. ${ }^{15}$ Table 1 summarizes the main features of Japanese VAT and the subsequent changes.

\footnotetext{
${ }^{10}$ Khanna and Yafeh (2005) provide a recent synthesis of international studies on business groups. See Yafeh (2000) for a review of studies on Japanese business groups and Granovetter (1995) for a review of sociology studies.

${ }^{11}$ The interests in the real effects dates back at least to Lintner and Butters (1955), who consider the role of progressivity in restricting the growth of large firms and reducing the concentration of businesses.

12 Studies on income shifting between personal and corporate tax bases raise caution about the interpretation of income inequality measures (Gordon and Slemrod, 1998; Sivadasan and Slemrod, 2006).

13 Ishi (2001) offers an overview of the Japanese VAT. National Tax Agency (2003) outlines the main features of VAT. Kaizuka (1992) provides historical backgrounds of the 1989 reform. Discussions by Noguchi (1992) and Hatta (1992) illustrate the main political issues from opposing perspectives. For international comparison, see Ebrill et al. (2001). In Japanese, Homma and Atoda (1989) discuss small business treatments and Kishi (1998) provides a narrative account of the reform process.

${ }^{14}$ Automobiles were taxed at $6 \%$ as a transition measure from the replaced indirect tax on automobiles, which was $23 \%$.

15 The LDP efforts to introduce a VAT were met with strong opposition; there were two failed attempts in 1979 and in 1987, and $71 \%$ of the public was against the tax bill in a poll conducted on 23 February 1989 (Ishi, 2001, p. 280). To win support from small businesses in passing a VAT bill, including from the Japan Chamber of Commerce and Industry (JCCI), a leading opposition group in the 1987 attempt, the LDP engaged in a series of dialogues with its business constituents. During April 1988, the LDP special committee on tax reform conducted hearings involving 338 organizations, including business associations and LDP local branches (Kishi, 1998, p. 137). The tax bill that finally passed included concessions for which JCCI expressed support.
} 
Table 1

Summary of Japanese VAT.

\begin{tabular}{|c|c|c|c|c|c|c|c|}
\hline \multirow[t]{2}{*}{ Enforced } & \multirow{2}{*}{$\begin{array}{l}\text { Rate } \\
\%\end{array}$} & \multicolumn{2}{|c|}{ Thresholds (mil. yen) ${ }^{1}$} & \multirow{2}{*}{$\begin{array}{l}\text { Presumed rates of VA } \\
\%\end{array}$} & \multirow[t]{2}{*}{ Other notable amendments } & \multirow[t]{2}{*}{ Enacted } & \multirow[t]{2}{*}{ Expectation ${ }^{7}$} \\
\hline & & Simplified & Exemption $^{2}$ & & & & \\
\hline$\overline{1989.4}$ & 3 & 500 & $30(60)$ & $20^{\mathrm{a}}, 10^{\mathrm{b}}$ & & 1988.12 & 1988.7 \\
\hline 1991.10 & 3 & 400 & $30(50)$ & $40^{\mathrm{a}}, 30^{\mathrm{c}}, 20^{\mathrm{d}}, 10^{\mathrm{b}}$ & Min. cap. law ${ }^{3}$, filing requirement ${ }^{4}$ & 1991.5 & 1991.4 \\
\hline 1997.4 & 5 & 200 & 30 & $50^{\mathrm{e}}, 40^{\mathrm{a}}, 30^{\mathrm{c}}, 20^{\mathrm{d}}, 10^{\mathrm{b}}$ & New business ${ }^{5}$ & 1994.11 & 1994.4 \\
\hline 2004.4 & 5 & 50 & 10 & $50^{\mathrm{e}}, 40^{\mathrm{a}}, 30^{\mathrm{c}}, 20^{\mathrm{d}}, 10^{\mathrm{b}}$ & Display method ${ }^{6}$ & 2003.3 & \\
\hline
\end{tabular}

Notes:

1. Sales level 2 years prior to the current tax year is used to determine eligibility.

2. The number in brackets is the upper limit of the phase-out scheme abolished in 1997.

3. The Commercial Law reform of 1990 introduced a minimum capital requirement of 10 million yen to incorporate a joint-stock corporation.

4. Entities paying more than 5 million yen in tax are required to file four times a year rather than two times a year.

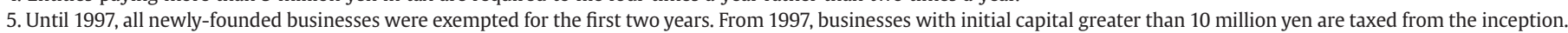
6. Sellers are required to display VAT-inclusive prices rather than before-tax prices (and adding VAT at the register).

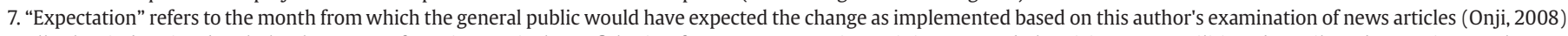

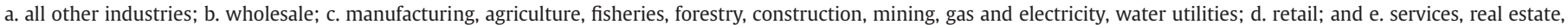
transport and communication (except eating and drinking places).

Source: Ishi (2001), Nihon Keizai Shinbun (various issues), National Tax Agency (2003).

Under the Consumption Tax Law of 1989, the special treatment for small businesses included the simplified filing scheme (SFS), which is analogues to the flat rate deduction experimented with in Italy (Tait, 1988). One of the main burdens in filing a VAT return is the computation of the amount of the tax credit which is based on VAT paid on inputs; a simplified return reduces compliance costs by presuming taxed inputs to be $80 \%$ of taxable sales. With the tax rate of $3 \%$, tax liability is simply $0.6 \%$ of taxable sales under SFS, thus converting a VAT into a turnover tax-a type of tax that a VAT is meant to improve upon. The eligibility for the simplified return is defined in terms of the amount of sales in a base period, which is 2 years prior to the current tax year, and the eligibility threshold is 500 million yen (\$3.3 million) under the 1989 system. It is common to adopt the amount of sales as the criteria, since it is generally viewed that the amount of sales is harder to manipulate than the number of employees. $^{16}$ The level of threshold covers a large number of corporations; in 1989, $96.7 \%$ of all businesses were eligible. ${ }^{17}$

\subsection{Legal viability of tax-motivated splitting}

The main issue, which leading scholars labelled as a "degradation of VAT" (Homma and Atoda, 1989), is the "hidden subsidy" resulting from excess tax credits. If the actual share of taxable inputs is less than the $80 \%$ of sales, a filer appropriates the tax collected from buyers on the difference between the presumed and actual value added. The scheme thus generates tax benefits and creates tax incentives to restructure organizations. The instrument for tax avoidance entails incorporating a segment of a company as a legally distinct entity with the sales size below the eligibility threshold. ${ }^{18}$ As a variant of this instrument, a firm may transfer a high value-added operation to a small entity already in existence. In this paper, these two types of instruments are referred to as a tax-motivated splitting.

Anticipating the behavioral response, Article 12 of the Consumption Tax Law provides against artificial splitting: for a divested entity that meets certain conditions, the eligibility is judged based on the

\footnotetext{
16 Tait (1988, p. 112) states without further documentation that when the exemption threshold was defined in terms of the number of employees in France, many small firms disappeared from statistics.

17 Those eligible entities accounted for $19 \%$ of the total turnover in the economy (Ishi, 2001, p282).

${ }^{18}$ The Commercial Law did not have an explicit notion of divesture until 2001 and the division in effect involves founding a new entity and possibly transferring assets. The taxation of corporate groups was not well developed at the time; a consolidated filing of corporate income tax was not introduced until 2002.
}

amount of sales consolidated with its divesting entity. ${ }^{19}$ However, the effectiveness of the anti-avoidance provision is questionable due to its limited scope and also due to the Japanese institutional framework for denying tax avoidance (Mizuno, 2005): Japan has not adopted a general anti-avoidance rule like those adopted in Australia and Germany; due to externalism in interpreting the law, case law has not yet established the "business purpose doctrine" to the degree existing in the US; the Japanese National Tax Agency is not generally as swift in denying new tax-avoidance strategies as the Internal Revenue Service in the US. It is thus reasonable to expect tax-motivated splitting to take place despite the legal provision against them.

This paper focuses on tax-motivated splitting, but other types of behavioral responses are conceivable: some small firms may forego sales to stay eligible (Keen and Mintz, 2004); filers of simplified returns may vertically consolidate, but stay below the threshold, to avoid tax cascading; ${ }^{20}$ sales may be underreported or their timing shifted across tax years; an assembler may provide inputs to keiretsu subcontractors and pay for "processing fees" rather than purchasing parts at the price inclusive of input costs.

\subsection{Costs and benefits}

There are tax incentives to shift sales into lightly taxed entities, but whether firms will conduct tax-motivated splitting depends on the relative magnitude of reorganization costs and tax benefits. To understand the economic viability of the avoidance strategy better, it is important to recognize that unlike the personal exemption under a typical individual income tax, where the tax liability is based on the portion of income exceeding the exempted amount, because the level of sales determines the benefit eligibility in the present setting, the

\footnotetext{
${ }^{19}$ For tax avoidance purposes, the new subsidiary must meet the conditions set out in the Article 12. Specifically, during the financial year in which the division took place, a divested entity is denied eligibility for SFS or exemption if (1) a new entity carries over whole or a part of the operation of the parent company; and (2) the initial capital of the new entity is contributed in kind in lieu of cash, among other conditions. For the subsequent financial years, the denial is limited to the case where, in addition to the previously stated conditions, (1) $50 \%$ or more of the stock is held by the parent company and its close relations and (2) the whole or a substantial part of the operation is classified as the same two-digit industry as the parent company. The conditions mean that the anti-avoidance provision is circumvented if the parent company contributes in cash, rather than in kind, to incorporate a new entity, leasing relevant assets required in the business operation. Establishing a company by investment in kind is a cumbersome method that involves assessment of assets by a third party and thus lacks popularity (Niiyama, 2001, p. 56).

20 The tax cascading arises only when two filers of simplified returns trade with one another. There is no incentive to merge for VAT purposes if there is no supplierpurchaser relationship.
} 


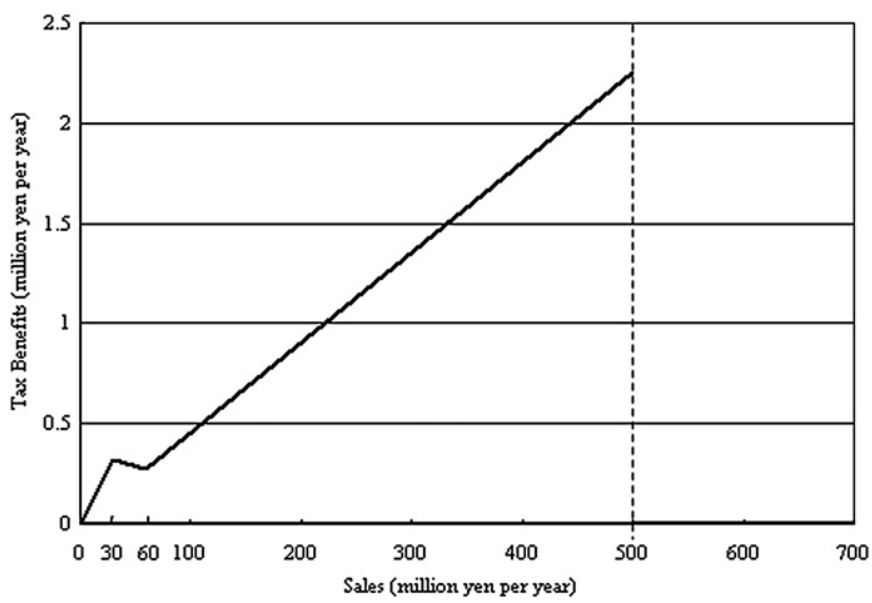

Fig. 1. Tax incentives under the 1989 VAT.

firm must keep the sales below the threshold level in order to benefit from SFS. As an illustration, Fig. 1 shows levels of tax benefit per annum for an entity with a value-added ratio of $35 \%$ and with a constant sales level over years. The tax benefit is generally increasing up to 500 million yen and is 2.25 million yen $(\$ 15,000)$ per annum at the maximum. ${ }^{21}$ Beyond the threshold the benefit eligibility is lost. Notice that tax benefits can accrue to a divesting entity, in addition to a divested entity, if the size of the divesting entity becomes sufficiently small, so that the potential gain from one split is higher than the peak amount in Fig. $1{ }^{22}$ Thus, there are tax incentives to split organization, but it requires a specific reconfiguration of the organizational structure. $^{23}$

Since firms need to alter the organizational structure from what it chose in the absence of the tax incentives, costs are likely to arise. The costs may include the aggravation of the principle-agent problem (Goolsbee and Maydew, 2002), administrative inconveniences and one-time administrative/ registration costs of founding a new corporation. ${ }^{24}$ Intuitively, the extent of these costs would vary, depending on, for instance, the flexibility of a business organization. There may be relatively little inconvenience in separating a small stand-alone division, but much confusion may arise by dividing an integrated operation into several legally separate entities. ${ }^{25}$ It is thus not plausible

\footnotetext{
${ }^{21}$ For brevity, we focus on the hidden subsidy arising from VAT. The full extent of tax benefits depends on income tax consequences. The hidden subsidy is a taxable income. But the divested entities are likely to be eligible for the preferential treatments of small entities under the taxes on corporate income. In net, the total tax benefits can in fact be greater than the hidden subsidy from VAT.

22 According to a press report, a producer of TV advertisements divided itself into four separate entities (Asahi Shinbun (evening edition), April 24, 1989).

${ }^{23}$ There are inter-temporal considerations that complicate the behavioral response but it is sensible to expect firms to respond to the discontinuity in tax treatment arising from the SFS threshold. One complication arises from the rule defining eligibility in terms of past sales. If a firm is sufficiently myopic, it is optimal to forgo future eligibility by increasing the current sales above 500 million yen to obtain extra current gain. Another complication is the rule on newly-founded entities. New entities were exempted from the VAT on the ground that they do not have prior sales records. The VAT exemption is beneficial, given that the subtraction method has been adopted in Japan. This rule adds to the incentives to create entities eligible for SFS but also generates incentives to create entities of any size. For firms with sufficiently low discount rates or with flexible organizations that are conducive to splitting, however, the size of divested entities is restricted below the threshold level-otherwise the tax benefits expire after the first two years.

${ }^{24}$ See World Bank (2007) for costs of starting up a business in Japan. One component of the transaction costs is the registration license tax, which is 7 mils of the paid-in capital with a minimum of 150,000 yen for founding of joint stock corporations.

${ }^{25}$ There may be small administrative inconvenience in splitting a corporate division physically separated from the other divisions. In expanding business to a new location, one retail company created a new company for tax purposes (People's Finance Corporation, 1994).
}

to expect complete segmentation of all corporations since not all organizational structure would be conducive to splitting. A more likely scenario is that firms are selective in choosing corporate divisions for which the tax-motivated splitting is economically viable.

Finally, Table 2 shows the level of hidden subsidy under the tax regimes of 1989 and 1991 to illustrate the variation in tax benefits across different activities. The average value-added ratios for each industry are shown in the first column and the presumed rates under the 1989 and 1991 regimes are shown in the second and third column respectively. ${ }^{26}$ Since the value added is diverse across industries but the presumed value added does not vary very much in 1989, the tax benefits vary as shown in the fourth column. For example, the tax benefit to an average real estate company with sales of 500 million is 3.8 million yen per year, which is 18 times as much as that to an average retail company. The amendment in October 1991 adjusted presumed rates, reducing the incentives, as shown in the last column.

Overall, the VAT reform should have induced some firms to selectively split off small divisions, particularly those stand-alone operations with high-value added, in ways that make new entities eligible for SFS.

\section{Evidence for tax-motivated splitting}

\subsection{Preliminary examination}

There are anecdotal cases of tax-motivated splitting reported in the press and in the study by a government-affiliated financial institution (People's Finance Corporation, 1994). They show the relevance of the tax incentives to some companies but do not indicate the extent of pervasiveness of the tax avoidance. As a preliminary examination, Fig. 2 plots the number of commercial registration of new corporations. Divested companies are required to file a commercial registration so tax-motivated splitting is captured in the statistics on newly registered companies unless the strategy involves transferring segments to existing small companies. The figure also includes the founding of stand-alone entities and existing businesses switching their form of organization. A surge of new registrations from 1988 to 1991 is consistent with the hypothesis of tax-motivated splitting ${ }^{27}$ since the reform would have been anticipated from June/July $1988 .{ }^{28}$ There are, however, alternative explanations, including one based on the "bubble economy": there was a rise in entrepreneurship as a result of the high level of domestic investment spurred by the loose monetary policy and by the rapid appreciation of the yen. ${ }^{29}$

\subsection{Examination of size distribution}

A natural way to identify the overall influence of a policy threshold would be to examine the size distribution of businesses in the neighborhood of the threshold. This paper implements kernel density

\footnotetext{
${ }^{26}$ There is an option to renounce SFS. The option reduces the risk of overpayment in case the value added falls below the presumed level. It is not perfect, since once registered to file a simplified return, the taxpayer can not opt out for the first two years. But the option increases the value of SFS by reducing uncertainty about the future value-added ratio.

27 The surge of founding, particularly that of the limited liability corporation, is partly due to the tax-motivated incorporations of sole proprietors, a phenomenon documented in various settings (e.g. Sivadasan and Slemrod, 2006). A new corporation, whether or not it is converted from a sole proprietor, is exempted from VAT. In 1990, the Justice Department responded by introducing a minimum capital requirement for incorporation. The spike in 1996 is caused by the changes in organizational form from joint-stock corporations to limited-liability corporations induced by the minimum capital requirement applicable to joint-stock corporations.

28 In June 1988, the proposal for the preferential treatment of small companies was publicized, and JCCI, the leading opposition to the earlier LDP initiative, publicized the acceptance of the reform. Nihon Keizai Shinbun, June 3 (evening edition), 1988.

29 See Cargill, Hutchison and Ito (1997) on the bubble economy of the late 1980s.
} 
Table 2

Industry variation in tax benefits.

\begin{tabular}{|c|c|c|c|c|c|}
\hline \multirow[t]{3}{*}{ Industry } & \multicolumn{3}{|c|}{$\begin{array}{l}\text { Value-added ratio } \\
(\%)\end{array}$} & \multicolumn{2}{|c|}{$\begin{array}{l}\text { Tax benefits }{ }^{\mathrm{b}} \\
\text { (mil. yen) }\end{array}$} \\
\hline & \multirow[t]{2}{*}{ Estimate $^{a}$} & \multicolumn{2}{|c|}{$\begin{array}{l}\text { Presumed } \\
\text { rate }\end{array}$} & \multirow[t]{2}{*}{$B_{1989}$} & \multirow[t]{2}{*}{$B_{1990}$} \\
\hline & & 1989 & 1991 & & \\
\hline Wholesale & 14.8 & 10 & 10 & 0.72 & 0.72 \\
\hline Retail & 21.4 & 20 & 20 & 0.21 & 0.21 \\
\hline Construction & 23.1 & 20 & 30 & 0.47 & 0 \\
\hline Mining & 29.0 & 20 & 30 & 1.35 & 0 \\
\hline Agricultural, forestry, and fisheries & 31.0 & 20 & 30 & 1.65 & 0.15 \\
\hline Manufacturing & 33.4 & 20 & 30 & 2.01 & 0.51 \\
\hline Services & 39.3 & 20 & 40 & 2.90 & 0 \\
\hline Transportation and telecommunications & 45.2 & 20 & 40 & 3.78 & 0.78 \\
\hline Real estate & 45.6 & 20 & 40 & 3.84 & 0.84 \\
\hline
\end{tabular}

Notes: a. Industry average reported by the Ministry of Finance in 1990 (Ishi, 2001, p. 293). b. Tax benefits $(B)$ is $B=\max \left[t s\left(v-v^{\prime}\right), 0\right]$, where $s$ is the amount of taxable sales, $t$ is the VAT rate, $v$ is the value-added ratio, and $v^{\prime}$ is the presumed value-added ratio. The max function captures the option to renounce the simplified scheme. Figures assume $s=500$ million yen and $t=0.03$.

estimation and compares the corporate size distributions in 1988 and $1990 .^{30}$ To be sure, different types of behavioral response result in a "bunching" near the threshold; there are incentives for simplifiedreturn filers to vertically consolidate but stay below the threshold, for instance. This paper interprets the bunching as evidence consistent with tax-motivated splitting and omits further examinations in the interest of brevity. ${ }^{31}$

There are three main issues in implementation. First, sales distributions may change over time for reasons unrelated to the tax structure, e.g., due to changes in underlying corporate attributes such as sectoral composition. To control for confounding influences, this study applies the density decomposition technique developed by DiNardo, Fortin and Lemieux (1996, hereafter denoted as DFL). ${ }^{32}$ Essentially the DFL decomposition technique is a generalization of the Oaxaca decomposition. The Oaxaca decomposition breaks down a mean wage gap between two groups of workers, such as male and female, into a component explained by the differences in the observable characteristics and that unexplained by the observables. Likewise, the DFL decomposition breaks down a distribution into explained and unexplained components. Rather than focusing on the mean of a distribution, the technique works on the whole distribution; for each level of sales, the difference in two distributions is decomposed into that explained by the observable characteristics and an unexplained component.

In application, we construct a counterfactual density function that would have prevailed after the tax reform if the distributions of company attributes had remained as they were before the reform. The counterfactual densities are estimated by weighting the post-reform sample to keep constant the distributions of company attributes of the pre-reform sample. See Appendix A for technical details. The component explained by differences in attributes is the difference between the actual post-reform distribution and the counterfactual distribution, since the latter reflects the influence of the taxes as in the post-reform distribution but keeps constant the attribute distributions at the pre-reform level. The residual component, which is the difference between the actual pre-reform distribution and the counterfactual distribution, is attributed as due to the tax reform. To our knowledge there were no concurrent institutional changes over

\footnotetext{
30 See DiNardo and Tobias (2001) for a review of nonparametric estimation techniques. 31 We have compared the size of new subsidiaries before and after the tax reform to test the tax-motivated splitting hypothesis directly. The results are reported in the working paper version of this paper (Onji, 2008).

32 The technique is widely applied in the study of wage distributions. See, for example, Butcher and DiNardo (2002), Chiquiar and Hanson (2005), and Johnson and Wilkins (2004).
}

the period 1988-1990 that introduced an institutional discontinuity at 500 million yen in sales. ${ }^{33}$

The second issue is the choice of control variables. Control variables include age, age squared, natural logarithm of paid-in capital (in million yen), natural logarithm of number of workers, indicator for public company, two-digit industry dummies and region dummies. A key assumption of DFL is that the distribution of control variables is unaffected by the VAT threshold: since the estimate of the threshold effects is the residual component, the threshold effects would be underestimation if the VAT threshold affects these control variables. Different specifications are tried to address this consideration-we have tried excluding paid-in capital, workers, and industry dummies that are suspected to capture some of the threshold effects-but this was not an important consideration in practice. To be conservative, the results presented below are based on a specification that includes all the controls. ${ }^{34}$

Third, the choice of bandwidth is a generic consideration in kernel density estimation (Pagan and Ullah, 1999; DiNardo and Tobias, 2001). The bandwidth is a smoothing parameter that affects density estimates, analogous to the bin width of the histogram that affects the appearance. For our application, it is important to recognize that the choice of bandwidth determines the range of observations that contribute in estimating the probability density function, or the "thickness" of a distribution, at a given level of sales. The rule of thumb in the general setting is to apply the optimal bandwidth formula, which incorporates the general features of a sample including the size and variance (Silverman, 1986).

However, it is well recognized that when the underlying data structure contains abrupt changes, such as peaks, the bandwidth based on the broad features of the whole distribution can perform poorly, causing a bias in the estimates around peaks. ${ }^{35}$ In the current context, the concern is the over-smoothing of the distribution around the threshold: the observations above the threshold contribute to the estimate of a density at a point below the threshold, thus possibly canceling out influences of the tax in a mechanical fashion. Therefore, the conventional optimal bandwidth would not be suitable when examining a local feature of a distribution such as threshold effects.

Here, we considered different levels of bandwidth $(0.3,0.2,0.1$, $0.08,0.06,0.04,0.02) .^{36}$ The bandwidth based on the rule-of-thethumb formula $\left(1.060 n^{-\frac{1}{5}}\right)$ is 0.33 and 0.35 for the 1988 and 1990 samples respectively. ${ }^{37}$ Following the practical approach in selecting the bandwidth by DiNardo and Tobias (2001), the benchmark analysis applies the common bandwidth of 0.08 which resulted in estimates

\footnotetext{
33 There are three factors that could have increased the founding of new subsidiaries of any size over the period. First, the introduction of the capital gain tax of 1989 induced some founders of family-controlled companies to found new subsidiaries and to transfer stocks to them in order to reduce inheritance tax liabilities (Nihon Keizai Shinbun, April $10,1990)$. Second, there was an increasing use of a tax avoidance strategy, known as the Japanese-style leverage leasing, during the economic boom of the late 1980s. The strategy involved establishing subsidiaries that lease physical assets such as airplanes (Nikkei Kinyu Shinbun, June 10,1991). Third, the economic boom might have amplified the incentives for tax avoidance, inducing tax-motivated splitting for corporate income tax purposes. Corporations filed separate income tax returns and small subsidiaries received preferential tax treatment. These three considerations do not, however, account for the observed changes near the threshold level.

${ }^{34}$ The company age variable may be a concern since the number of young companies would increase due to tax-motivated splitting, but since newly created companies are but a small fraction of the overall sample, they are unlikely to affect the age distribution at large. ${ }^{35}$ See the discussion on the local bandwidth estimation problem (for instance, Brockmann et al., 1993).

${ }^{36}$ For brevity, we omit the results with different levels of bandwidth. We have implemented statistical tests commonly used to compare distributions (Burkhauser et al. 1999). These results are reported in the working paper version of this paper (Onji, 2008). 37 Note that the optimal bandwidth differs by samples, as it depends on the sample size $(n)$ and standard deviation $(\sigma)$. Thus, for a valid comparison, it may be preferable to vary the bandwidth by varying the percent reduction from the optimal bandwidth rather than using different levels of common bandwidth. This alternative method was implemented but the results were not sensitive to the change.
} 


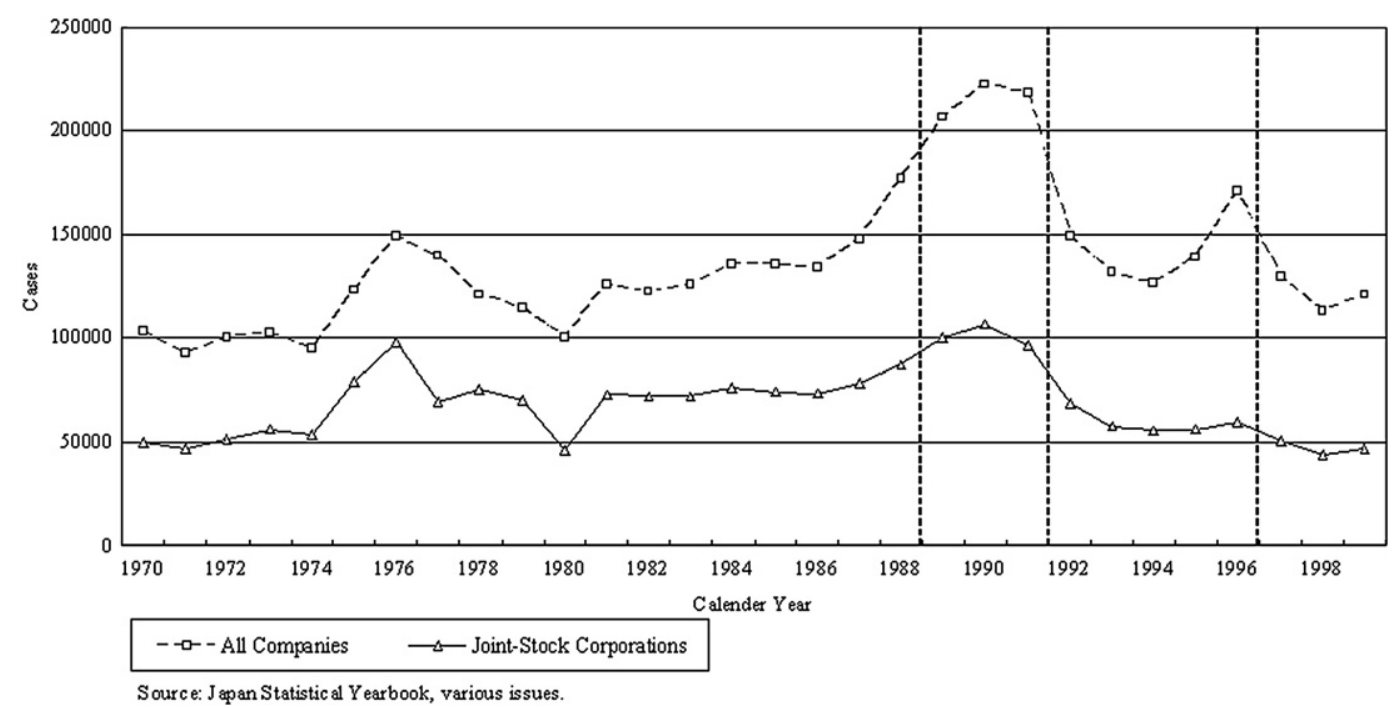

Fig. 2. The number of commercial registrations (founding).

that do not appear to be oversmoothed or undersmoothed. This bandwidth implies that the information on companies from 418 to 598 million yen is used to estimate the density at $\ln 500$.

\subsection{Data}

The Affiliated Company Data (ACD) is based on an annual survey conducted by Toyo Keizai Inc. that asks parent companies for information about their affiliates. The surveyed companies include all publicly traded companies and a small number of prominent privatelyheld companies such as IBM Japan. ${ }^{38}$ This study uses as the pre-reform sample the 1990 ACD, which contains information from FY1988; the post-reform sample is the 1992 ACD that contains FY1990 data. A total of 75.7 and $78.4 \%$ of surveyed parent companies appear in 1990 and 1992 ACD respectively, but missing variables reduce the coverage. As the tax reform was anticipated during FY1988 corporations would have had time to respond to the anticipated change. ${ }^{39}$ The FY1988 sample may capture pre-reform responses, in which case it leads a downward estimate of the impacts of the reform. Though the survey itself has been conducted since the early 1980s, the earliest sample available in electronic format is the 1990 ACD. Notice that in evaluating the response to the tax changes at the corporate group level, ACD offers an important information source; a splitting for VAT purposes is equivalent to a creation of a new subsidiary. Additions of new companies, as well as the size reduction of the divesting entities, are reflected in the data. All corporations in the sample are taxed separately under the VAT except for those that do not meet the anti-avoidance provision.

The parent companies and subsidiaries in ACD account for a significant fraction of the Japanese economy. In 1988, the surveyed companies account for $57.4 \%$ of paid-in capital, $43.3 \%$ of after-tax profit,

\footnotetext{
38 Survey items include company characteristics (company name, address of headquarters, contact telephone number, two-digit industry classification, main activity, the percentage of voting stock held within the group, number of workers, date of founding, form of incorporation) and financial information (fiscal year, paid-in capital, sales, after-tax profit, dividend). The electronic version of the data contains parents' stock market codes, child-company identifiers, two-digit industry codes and region codes. See Onji (2005) for further description. An example of data is available from the publisher at http://www.toyokeizai.co.jp/db/pdf/kankeikaisha.pdf (Accessed Nov. 1, 2007).

${ }^{39}$ The reform law was first passed by the Lower House in November 1988, but the reform proposal, which eventually passed with minor amendments, became known to the public on June 15, 1988 (Ishi, 2001, p. 276).
}

and $18.3 \%$ of employees in the corporate sector excluding financial and insurance companies. ${ }^{40}$ It is therefore an appropriate dataset to understand the behavior of corporations operating in the influential segment of the economy, but two qualifications are in order.

First, the sample consists of relatively large corporations. Table 3 presents the distribution of corporate size in terms of paid-in capital. The distribution is heavily skewed to the left for the population: in 1988, nearly $80 \%$ of corporations were in the smallest size category, but the sample is relatively dense on the right-under $10 \%$ is contained in the smallest size category. Thus, small corporate groups headed by nonpublic companies are not in the sample-a possible source of underestimation of the threshold effects on the universe of businesses. Second, the corporations in the sample are members of corporate groups but most corporations in the population are independent; according to the 2001 Establishment and Enterprise Census, just 4.8\% of all corporations are affiliated with another company, though corporate groups account for $43.9 \%$ of private-sector employment. ${ }^{41}$ The focus on affiliated companies allows us to target groups in which the behavioral response is likely to be stronger. If stand-alone entities are analyzed, the impact on the distribution may be weaker. Overall, caution is required in extrapolating our finding to the population, but the sample represents a segment of the economy that has independent interest of its own.

The sample is restricted to observations that contain required variables and that were in existence for at least 1 year prior to the beginning of the fiscal year. There are overlapping observations in the raw data set due to the survey process. These have been removed from the sample, unless they are the head of another group, or a subsidiary of a head reported as a subsidiary in another group. The summary statistics are presented in Table 4.

\section{Results}

Fig. 3 plots the kernel density estimates of the natural log of sales for FY1988 (long-dotted line) and FY1990 (solid line). The differences

\footnotetext{
40 The population figure is based on Ministry of Finance, Financial Statement Statistics of Corporations available from http://www.mof.go.jp/english/e1c002.htm (Accessed 8 August 2008).

41 The summary of the EEC is published in Japanese at the website of the Statistics Bureau, Government of Japan (http://www.stat.go.jp/data/jigyou/2001/index2.htm, Accessed 8 August 2008). 2001 is the only year for which the Bureau publicizes the results aggregated over corporate groups.
} 
Table 3

The number of corporations by the size of capital.

\begin{tabular}{lllllll}
\hline \multirow{2}{*}{ Year } & Data & \multicolumn{5}{c}{ Size categories (paid-in capital, million yen) } \\
\cline { 3 - 7 } & & All sizes & {$[0,10)$} & {$[10,100)$} & {$[100,1000)$} & {$[1000$, ) } \\
\hline 1988 & Population & $1,980,540$ & $1,583,805$ & 376,205 & 17,442 & 3,088 \\
& & & $(79.97)$ & $(19.00)$ & $(0.88)$ & $(0.16)$ \\
1988 & \multirow{2}{*}{ Sample } & \multirow{2}{*}{13,760} & 1,316 & 6,833 & 3,439 & 2,172 \\
& & & $(9.56)$ & $(49.66)$ & $(24.99)$ & $(15.78)$ \\
1990 & \multirow{2}{*}{ Population } & \multirow{2}{*}{$2,020,455$} & $1,590,035$ & 406,618 & 19,997 & 3,805 \\
& & & $(78.70)$ & $(20.13)$ & $(0.99)$ & $(0.19)$ \\
1990 & \multirow{2}{*}{ Sample } & \multirow{2}{*}{15,901} & 1,420 & 8,081 & 3,863 & 2,537 \\
& & & $(8.93)$ & $(50.82)$ & $(24.29)$ & $(15.95)$ \\
\hline
\end{tabular}

Notes: Number of corporations. Percentage of all sizes are in parentheses. The population figures are based on the estimates by the Ministry of Finance, Financial Statement Data. The sample figures are based on this author's calculation using the samples.

in these densities show the raw difference that lump together the effects attributable to the tax threshold with those attributable to the changes in company attributes. The figure also superimposes the counterfactual densities estimated with the DFL method (shortdotted line) that control for the changes in company attributes (i.e. the distribution that would have prevailed in 1990 had the distributions of company attributes remained as they were in 1988). The vertical line indicates the threshold level of sales (the natural log of 500). The density estimates are based on the bandwidth of 0.08 .

We consider first the actual change in densities. Around the threshold level of sales the post-reform densities are thicker than the pre-reform densities and there is an indication of a "bunching" below the threshold in the FY1990 distribution. Above the threshold the prereform densities are thicker over some ranges and the two lines become close for higher level of sales. The response based on the anticipated change might have resulted in a dip near the threshold point in the FY1988 distribution. ${ }^{42}$ As a clearer illustration of the change, Fig. 4 plots the differences in the actual densities (solid line). The increase at the threshold point is equivalent to an $12.4 \%$ increase from the 1988 level; the largest change near the threshold occurs at the sales level of 475 million yen, where the density increases by $15.5 \%$. Over the range $[570,990]$ the densities decline. The increase over the range $[500,570]$ is likely to be due to the oversmoothing. At face value, this pattern is indicative of a movement of mass from size above the threshold to below-a pattern that would arise had there been a pervasive incidence of corporate splitting.

To see if the actual change is explained away by the changes in attributes, we now turn to the DFL decomposition. The component attributable to the changes in control variables is the difference between the actual FY1990 densities and the counterfactual densities (short-dotted line labelled “ $\triangle$ Attributes" in Fig. 4). The residual component, obtained by subtracting the explained component from the overall change, is attributed to the effects of the tax reform (long-dotted line labelled " $\triangle$ Institution"). In the neighborhood of the threshold, the residual components are very close to the actual changes; $95 \%$ of the change at the threshold point is attributable to the tax threshold effects. Thus, this analysis rules out an explanation that the differences in attributes are the reason for the increase in density near the threshold; the pattern can be interpreted as being caused by the tax law change.

\footnotetext{
42 One corporate group in the data founded a subsidiary in November 1988, when the VAT bill passed through the Lower House, that shared with a group member the company representative, telephone number, and address. The sum of sales of two companies for FY1988 was 529 million yen. This reorganization is suggestive as due to an anticipated response.
}

Notably, the reduction in the mass beyond the threshold point is much pronounced. Over the range of sales [560, 1080], the longdotted line is in the negative range and is greater in magnitude than the solid line, suggesting that changes in attributes masked some of the threshold effects over this range. Note that the range roughly corresponds to the range $(500,1000]$ where there are stronger incentives to split corporations. Since divesting entities in the size range would become eligible for SFS when the division is successful, groups can shift a sales amount greater than 500 million yen to be taxed under the preferential status. Whereas if the tax status of divesting corporations does not change, the maximum amount of sales that can be shifted is at most 500 million yen per splitting.

While the clustering near the threshold may in part be due to behavioral responses other than splitting, it is difficult to attribute the decline above the threshold to other types of responses alone; mergers of small affiliates should not affect the density above the threshold, and it would be implausible that a firm would forego as much as $\mathbf{5 0 0}$ million yen worth of sales. The pattern is consistent with the prevalence of tax-motivated splitting, though misreporting of sales would still be a relevant form of response.

\section{Concluding remarks}

This paper documents the effects of a tax threshold on firm behavior in the context of the Japanese VAT. A comparison of size distributions before and after the tax reform of 1989 reveals a "bunching" below the eligibility threshold for SFS, indicating a prevalence of tax avoidance to take advantage of the preferential treatment of small businesses. We found that the bunching is attributable to the tax reform rather than confounding influences of the changes in company attributes across 1988-1990; we applied a semiparametric density decomposition technique developed by DiNardo et al. (1996) to net out confounding influences. We interpret the evidence as being consistent with the hypothesis that large firms are "masquerading" as many small firms.

There are three directions of possible extensions to the analysis presented. First is further examination on the types of behavioral responses. The tax-motivated splitting explain the overall pattern better than some other tax-based explanations; a closer examination of a founding pattern of new subsidiaries would complement the current study in offering further evidence on corporate splitting.

Table 4

Summary statistics.

\begin{tabular}{llll}
\hline Variables & 1988 & 1990 & All \\
\hline In (amount of sales) & $7.835(7.636)$ & $7.844(7.665)$ & $7.840(7650)$ \\
Age (months) & $280.3(230.0)$ & $278.0(229.0)$ & $279.1(230.0)$ \\
In (amount of paid-in capital) & $4.514(3.912)$ & $4.517(3.912)$ & $4.516(3.912)$ \\
In (number of workers) & $4.341(4.263)$ & $4.243(4.143)$ & $4.289(4.190)$ \\
Number of group members & $31.1(17.0)$ & $33.8(18.0)$ & $32.5(18.0)$ \\
Voting shares held in group (\%) & $62.4(70.0)$ & $63.3(71.9)$ & $62.9(70.0)$ \\
& & & \\
Indicators & & & \\
Publicly traded & 0.139 & 0.133 & 0.136 \\
Shares the same address as parent ${ }^{\mathrm{a}}$ & 0.259 & 0.274 & 0.267 \\
Sales at or less than 500 million & 0.224 & 0.223 & 0.223 \\
Wholesale & 0.118 & 0.120 & 0.119 \\
Retail & 0.076 & 0.076 & 0.076 \\
Construction and mining & 0.062 & 0.065 & 0.063 \\
Agriculture, forestry, and fishery & 0.005 & 0.004 & 0.005 \\
Manufacturing & 0.360 & 0.356 & 0.358 \\
Service & 0.116 & 0.166 & 0.143 \\
Transportation and communication & 0.089 & 0.091 & 0.090 \\
Financial and real estate & 0.089 & 0.096 & 0.093 \\
Others & 0.084 & 0.025 & 0.053 \\
Observations & 13,760 & 15,901 & 29,661 \\
\hline
\end{tabular}

Notes: The figures are sample averages for continuous variables and proportions for dummy variables. Standard deviations are in parentheses.

a Parent companies are excluded in computation. 


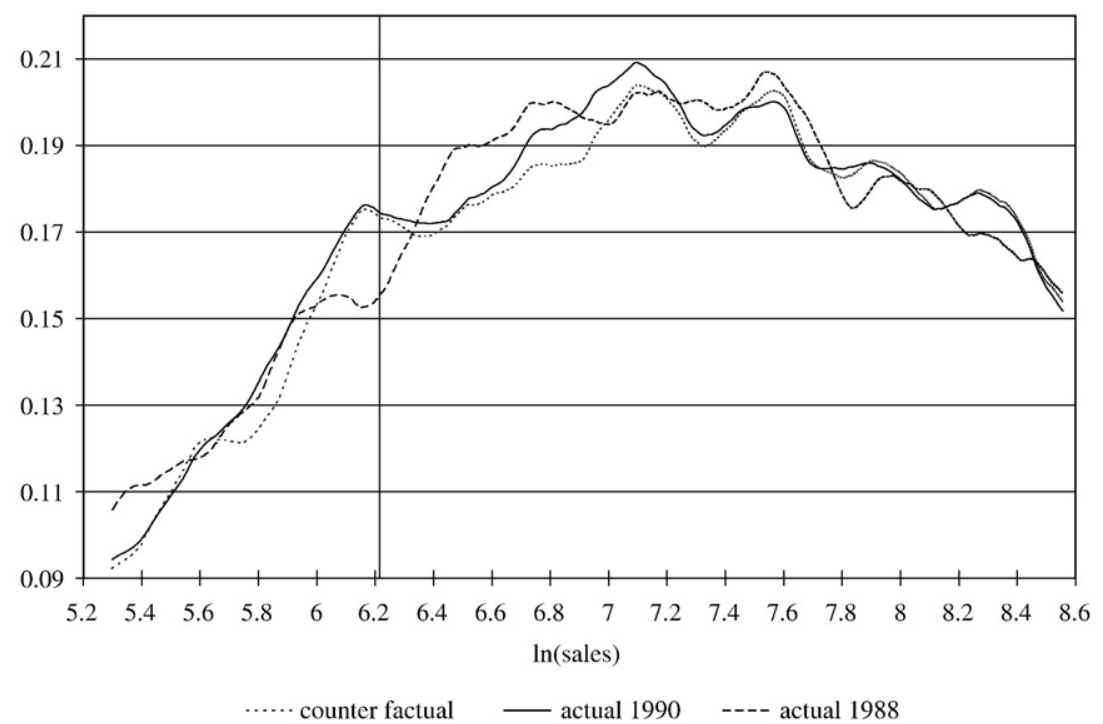

Fig. 3. The plots of density estimates.

Second is the analysis of revenue/efficiency consequences. While the assumptions required in the identification of threshold effects are reasonably weak, the present approach is not suitable for estimating revenue losses. By understanding the tax gains to firms, we learn about the extent of revenue drains caused by tax avoidance, but we can also gauge the extent of efficiency losses. The efficiency losses can occur by maintaining organizational structures that firms would not have chosen otherwise (e.g. Goolsbee and Maydew, 2002). But since a rational firm would not incur costs greater than the benefits, the amount of tax benefits provides the upper bound for the efficiency loss. Third is the examination in the other policy settings. We have noted that the institutional framework for denying tax-avoidance is relatively weak in Japan compared to the US. It would be of interest to see if large firms "masquerade" in a setting where there are tighter legal restrictions. Finally, eligibility thresholds are common components in a host of public policies that favor small over large firms. In this author's opinion, it seems likely that the masquerading by firms is left undocumented in the context of taxes as well as regulatory systems in various countries around the world.

\section{Acknowledgements}

This paper is a substantially revised version of my doctoral dissertation completed at UCSD. I am indebted to Roger Gordon for the generous guidance during the course of my study. Special thanks are due to Gordon Hanson, Takeo Hoshi and Nora Gordon for the vital help in developing this research. I am grateful to Joel Slemrod, the editor, and the anonymous referees for comments on the draft. I wish to thank Kate Antonovics, Julie Cullen, Mihir Desai, Ted Groves, Charles Yuji Horioka, Marc Muendler, Valerie Ramey, Ross Star and the participants at the UCSD, Osaka University, NBER-Japan Project 2007 and ANU for the helpful comments and suggestions. The Joseph Naiman Fellowship in Japanese Studies and the Pacific Basin Endowment Fellowship provided the funding. All remaining errors in this paper are mine.

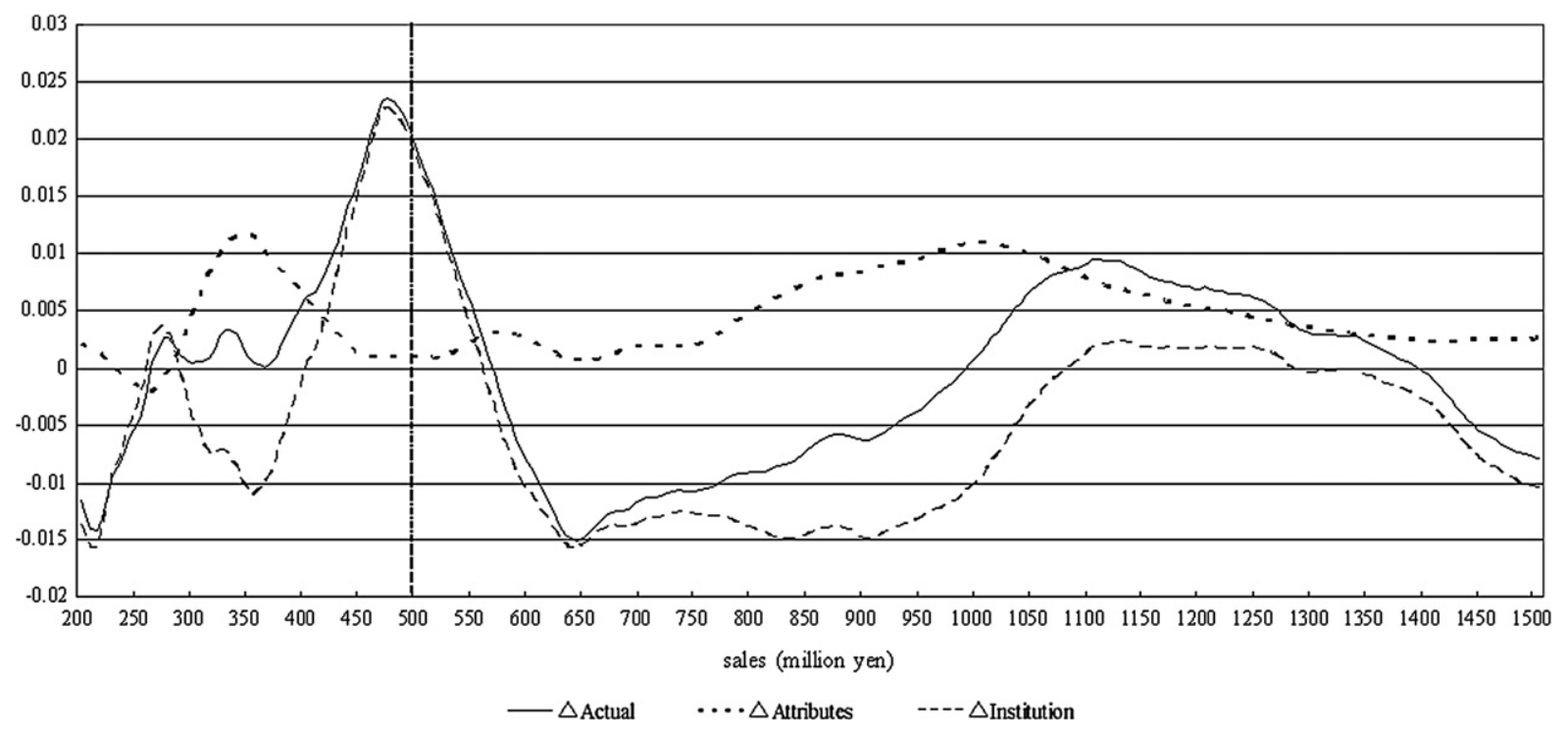

Fig. 4. The decomposition of density changes: 1988-1990. 


\section{Appendix A. Application of DFL}

\section{Notations and assumptions}

This section outlines the application of the DFL decomposition technique following Chiquiar and Hanson (2005). $y$ is a natural logarithm of sales (in million yen), $x=\left\{x_{1}, x_{2}, \ldots, x_{n}\right\}$ is a vector of $n$ company attributes and $t$ is a time period. Each observation is thought of as a vector $(y, x)$ that belongs to a joint distribution $F(y, x \mid t)$ at a given point in time. The probability density function for this joint distribution is denoted as $f(y, x \mid t)$. Note that the shape of a joint density at time $t$ can depend on institutional factors, including a tax threshold. The conditional density function of $y$ on $x$ can be written as:

$g(y \mid x, t)=f(y, x \mid t) / l(x \mid t)$

where $l(x \mid t)$ is the marginal density of $x$ at time $t$. By rearranging the expression and taking the integral over the domain of $x$, which is denoted as $\Omega_{x}$, we obtain

$f(y \mid t)=\int_{x \in \Omega_{x}} f(y, x \mid t) d x=\int_{x \in \Omega_{x}} g(y \mid x, t) l(x \mid t) d x$

The middle expression of (2) is the marginal density of $y$ at time $t$ since the marginal density of $y$ can be obtained by integrating over $x$, given that $y$ and $x$ have a joint density (Golberg, 1984).

Eq. (2) shows that changes in the density of $y$ can occur through changes in the shape of the conditional density $g($.$) and through the$ distribution of $x$. If the threshold causes clustering of corporations at $y=\ln (500)$, then

$g(y=\ln 500 \mid x, t=1990)>g(y=\ln 500 \mid x, t=1988)$

for some representative level of $x$. In addition, if the threshold affects density around $y=\ln (500)$, the effects are captured by the difference between $g(\hat{y} \mid x, t=1990)$ and $g(\hat{y} \mid x, t=1988)$, where $\hat{y}$ represents a value of $y$ in the neighborhood of 500 million. On the other hand, if the density of $y$ changes due to changes in sectoral composition, for example, such an effect causes the distribution of $x$ to change. This effect is represented by the difference between $l(x \mid t=1990)$ and $l(x \mid t=1988)$.

The following expression is the counterfactual density that would have prevailed in 1990, had the distribution of company characteristics remained as it was in 1988.

$\int_{x \in \Omega_{x}} g(y \mid x, t=1990) l(x \mid t=1988) d x$

To make the substitution for the density of $x$ in this expression, it is assumed that the distribution of attributes and the conditional distribution are "independent" of one another. Specifically, it is presumed that the tax change, which is thought to affect the conditional distribution, does not affect the distribution of attributes. In addition, the assumption means that the distribution of attributes will not affect sales conditional on $x .^{43}$ If there was an increase in the number of companies in a particular industry, for example, this assumption requires that the goods demanded in the industry increase accordingly, so that companies are not constrained to sell less.

The economy grew robustly by $10.7 \%$ over the period $1988-1990$ and the price level, in terms of the GDP deflator, increased by $4.8 \%$. These changes are likely to affect the overall shape of the distribution,

\footnotetext{
43 In the study by DFL on wage distributions, it is assumed that wage structures do not depend on the underlying distribution of attributes, such as education levels. For instance, this assumption rules out the possibility that an increase in the supply of educated labor force reduces the return to education.
}

including the mean and the spread, but since the analysis on threshold effects is unlikely to be affected, the macroeconomic changes are not considered here.

\section{Hypothetical density}

To make the counterfactual density estimable, it is re-expressed as follows.

$$
\begin{aligned}
& \int_{x \in \Omega_{x}} g(y \mid x, t=1990) l(x \mid t=1988) d x \\
& =\int_{x \in \Omega_{x}} \frac{l(x \mid t=1988)}{l(x \mid t=1990)} g(y \mid x, t=1990) l(x \mid t=1990) d x \\
& =\int x \in \Omega_{x} \theta g(y \mid x, t=1990) l(x \mid t=1990) d x,
\end{aligned}
$$

where $\theta \equiv \frac{l(x \mid t=1988)}{l(x \mid t=1990)}$. Note that the counterfactual density is equivalent to the 1990 density, except for the weighting function $\theta$. As shown by DFL, this weight can be simplified by using Bayes' rule: $l(x)=\frac{l(x \mid t) P(t)}{P(t \mid x)}$.

$\theta=\frac{P(t=1988 \mid x)}{P(t=1990 \mid x)} \frac{P(t=1990)}{P(t=1988)}$

Using the combined sample of FY1988 and FY1990 data, $P(t=1988 \mid x)$ is estimated parametrically by running a probit on the observation belonging to the 1988 sample. Control variables are as described in the text. The rest of the terms in the weighting function (6) are computed as follows: $P(t=1990 \mid x)=1-P(t=1988 \mid x), P(t=1990)$ and $P(t=1988)$ are the proportions of the 1990 and 1988 observations, respectively.

\section{Kernel density estimation}

The counterfactual density is estimated with the Rosenblatt-Pazen kernel density estimator that is adopted in the case where the observations have sample weight (Chiquiar and Hanson, 2005),

$\int_{x \in \Omega_{x}} \hat{\theta} g(y \mid x, t=1990) l(x \mid t=1990) d x=\sum_{i=1}^{n} \frac{\hat{\theta}_{i}}{h} K\left(\frac{y-Y_{i}}{h}\right)$

where $i=1, \ldots, n$ are observations from the FY1990 sample. $\theta$ is the estimated weight based on (6) and $h$ is the bandwidth. $K($.$) is the$ kernel function that determines, along with the bandwidth, how observations are weighted in the estimation process. Since it is largely agreed that the choice of kernel function is unimportant, this paper uses Epanechnikov kernel function ${ }^{44}$ that has a convenient property of being truncated at points, providing us with information on the range of support involved in estimating a density at each point. ${ }^{45}$ The discussion on the bandwidth choice is in the text.

\section{References}

Acemogle, A., Angrist, J.D., 2001. Consequences of employment protection? The case of the Americans with Disabilities Act. Journal of Political Economy 109, 915-957.

Auerbach, A.J., Reishus, D., 1988. The impact of taxation on mergers and acquisitions. In: Auerbach, A.J. (Ed.), Mergers and Acquisitions. University of Chicago Press, London, pp. 69-85.

Baldwin, J.R., Gorecki, P.K., 1985. The determinants of small plant market share in Canadian manufacturing industries in the 1970s. Review of Economics and Statistics 67, 156-161.

Brockmann, M., Gasser, T., Herrmann, E., 1993. Locally adaptive bandwidth choice for kernel regression estimators. Journal of the American Statistical Association 88, 1302-1309.

Butcher, K.F., DiNardo, J., 2002. The immigrant and native-born wage distributions: evidence from United States censuses. Industrial and Labor Relations Review 56, 97-121.

Burkhauser, R.V., Cutts, A.C., Daly, M.C., Jenkins, S.P., 1999. Testing the significance of income distribution changes over the 1980s business cycle: a cross-national comparison. Journal of Applied Econometrics 14, 253-272.

\footnotetext{
${ }^{44} K(z)=\frac{3}{4 \sqrt{5}}\left(1-\frac{1}{5} z^{2}\right)$ if $|z|<\sqrt{5}$ and 0 otherwise.

45 See DiNardo and Tobias (2001) for a range of kernel functions.
} 
Cabral, L.M., Mata, J., 2003. On the evolution of the firm size distribution: facts and theory. American Economic Review 93, 1075-1090.

Callan, S.J., Thomas, J.M., 2004. Environmental Economics and Management: Theory, Policy, and Applications. Thomson/South-Western, OH.

Cargill, T.F., Hutchison, M.M., Ito, T., 1997. The Political Economy of Japanese Monetary Policy. MIT Press, MA

Chiquiar, D., Hanson, G.H., 2005. International migration, self-selection, and the distribution of wages: evidence from Mexico and the United States. Journal of Political Economy 113, 239-281.

Curry, B., George, K.D., 1983. Industrial concentration: a survey. Journal of Industrial Economics 31, 203-255

DiNardo, J., Fortin, N.M., Lemieux, T., 1996. Labor market institutions and the distribution of wages, 1973-1992: a semiparametric approach. Econometrica 64, 1001-1044.

DiNardo, J., Tobias, J.L., 2001. Nonparametric density and regression estimation. Journal of Economic Perspectives 15, 11-28.

Dixon, P.B., Picton, M.R., Rimmer, M.T., 2004. Payroll taxes: thresholds, firm sizes, deadweight losses and commonwealth grants commission funding. Economic Record 80, 289-301.

Ebrill, L., Keen, M., Bodin, J.P., Summers, V., 2001. The Modern VAT. IMF, Washington D.C.

Flath, D., 2005. The Japanese Economy, 2nd Ed. Oxford University Press, Oxford.

Golberg, M.A., 1984. An Introduction to Probability Theory With Statistical Applications. Plenum Press, New York.

Goolsbee, A., Maydew, E., 2002. Taxes and organizational form: the case of REIT spinoffs. National Tax Journal 55, 441-456.

Gordon, R.H., MacKie-Mason, J.K., 1990. Effects of the tax reform act of 1986 on corporate financial policy and organizational form. In: Slemrod, J. (Ed.), Do Taxes Matter? MIT Press, MA, pp. 91-131.

Gordon, R.H., MacKie-Mason, J.K., 1994. Tax distortions to the choice of organizational form. Journal of Public Economics 55, 279-306.

Gordon, R.H., MacKie-Mason, J.K., 1997. How much do taxes discourage incorporation? Journal of Finance 52, 477-505.

Gordon, R.H., Slemrod, J. Are "Real" Responses to Taxes Simply Income Shifting Between Corporate and Personal Tax Base? NBER Working Papers 1998; 6576.

Granovetter, M., 1995. Coase revisited: business groups in the modern economy. Industrial and Corporate Change 4, 93-130.

Grubert, H., Mutti, J., 1991. Taxes, tariffs and transfer pricing in multinational corporate decision making. Review of Economics and Statistics 73, 285-293.

Grubert, H., Slemrod, J., 1998. The effect of taxes on investment and income shifting to Puerto Rico. Review of Economics and Statistics 80, 365-373.

Hart, P.E., Oulton, N., 1997. Zipf and the size distribution of firms. Applied Economics Letters 4, 205-206.

Hatta, T., 1992. The Nakasone-Takeshita tax reform: a critical evaluation. American Economic Review 82, 231-236.

Hines, J.R., Rice, E.M., 1994. Fiscal paradise: foreign tax havens and American business. Quarterly Journal of Economics 109, 149-182.

Homma, M., Atoda, N., 1989. Zeisei kaikaku no jittshou bunseki. (The Empirical Analysis of the Tax Reform). Toyokeizai, Tokyo.

Hu, M., 1999. The determinants of SMEs' market share in 1991-Taiwan manufacturers. Small Business Economics 12, 1-9.

Ishi, H., 2001. The Japanese Tax System. Oxford University Press, Oxford.

Johnson, D., Wilkins, R., 2004. Effects of changes in family composition and employment patterns on the distribution of income in Australia: 1981-1982 to 1997-1998. Economic Record 80, 219-238.

Kaizuka, K., 1992. The Shoup tax system and the postwar development of the Japanese economy. American Economic Review 82, 221-225.

Keen, M., Mintz, J., 2004. The optimal threshold for a value-added tax. Journal of Public Economics 88, 559-576.

Khanna, T., Yafeh, Y., 2005. Business groups and risk sharing around the world. Journal of Business 78, 301-340.

Kishi, N., 1998. Zei no koubou. (Struggles for a Tax Reform). Bungei Shunjun, Tokyo.

Lintner, J., Butters, KJ. 1955. Effects of taxes on concentration. Business Concentration and Price Policy. Princeton University Press, NJ, pp. 239-275.
Lucas Jr, R.E., 1978. On the size distribution of business firms. Bell Journal of Economics 9, 508-523.

Matasar, A.B., Heiney, J.N., 2002. The Impact of Geographic Deregulation on the American Banking Industry. Quorum Books, CT.

Mizuno, T., 2005. Sozeihou. (Tax Law). Yuhikaku, Tokyo.

National Tax Agency, 2003. An Outline of Japanese Tax Administration. National Tax Agency, Tokyo. Available from http://www.nta.go.jp/foreign_language/ report2003/text/02/01.htm\#a-4_06 (accessed 8 August 2008).

Niiyama, Y., 2001. Kaishahou no shikumi to hataraki. (Company Law: Structure and Function). Nihon Hyouronsha, Tokyo.

Noguchi, Y., 1992. The changing Japanese economy and the need for a fundamental shift in the tax system. American Economic Review 82, 226-230.

Onji, K., 2005. Taxation and the Behavior of Corporate Groups, PhD Thesis, University of California at San Diego.

Onji, K., 2008. The Response of Firms to Eligibility Thresholds: Evidence From the Japanese Value-Added Tax. Asia Pacific Economic Papers.

Pagan, A., Ullah, A., 1999. Nonparametric Econometrics. Cambridge University Press, Cambridge.

Pedone, A., 1981. Italy. The Value-Added Tax: Lessons From Europe. The Brookings Institution, Washington D.C., pp. 31-42.

People's Finance Corporation, 1994. Bunsha suru chuushou kigyou: Seijuku jidai no keiei kakushin. (The Corporate Divesture of Small and Medium Sized Enterprises: Innovative Management in the Mature Economy). Chuushoukigyou Risachi Senta, Tokyo.

Schivardi, F., Torrini, R., 2004. Threshold Effects and Firm Size: The Case of Firing Costs. CEP Discussion Papers.

Schmalensee, R., 1988. Industrial economics: an overview. Economic Journal 98, 643-681.

Schmalensee, R. 1989. I. In: Schmalensee, R. Willing, R.D. (Eds.), Inter-Industry Studies of Structure and Performance. . Handbook of Industrial Organization, vol. II. Elsevier Science, New York, pp. 951-1009.

Scholes, M.S., Wolfson, M.A., 1990. The effects of changes in tax laws on corporate reorganization activity. Journal of Business \& Economic Statistics 63, 141-164.

Scholes, M.S., Wolfson, M.A., Erickson, M., Maydew, E.L., Shevlin, T., 2002. Taxes and Business Strategy: A Planning Approach. Prentice Hall, NJ.

Silverman, B., 1986. Density Estimation for Statistics and Data Analysis. Chapman and Hall, London.

Sivadasan, J., Slemrod, J., Tax Law Changes, Income Shifting and Measured Wage Inequality: Evidence From India. NBER Working Papers 2006; 12,240.

Stanley, M.H.R., Buldyev, S.V., Havlin, S., Mantegna, R.N., Salinger, M.A., Stanley, H.E., 1995. Zipf plots and the size distribution of firms. Economics Letters 49, 453-457.

Stephens, M., Ward-Batts, J., 2004. The impact of separate taxation on the intrahousehold allocation of assets: evidence from the UK. Journal of Public Economics 88, 1989-2007.

Tait, A.A., 1988. Value Added Tax: International Practice and Problems. International Monetary Fund:, Washington, D.C.

Viscusi, W.K., Vernon, J.M., Harrington, J.E., 2001. Economics of Regulation and Antitrust. MIT Press, MA.

Westney, D.E., 1998. In: Drysdale, P., Gower, L. (Eds.), The Japanese Business System: Key Features and Prospects for Change. The Japanese economy, Part 1, vol. 4. Routledge, London, pp. 151-175.

Williamson, O.E., 1985. The Economic Institution of Capitalism. Free Press, NY.

White, L.J., 1982. The determinants of the relative importance of small business. Review of Economics and Statistics 64, 42-49.

World Bank, 2007. Doing Business 2008: Japan. World Bank, Washington. Available from http:// www.doingbusiness.org/Documents/CountryProfiles/JPN.pdf (accessed 15 October 2007).

Wren, C., Storey, D.J., 2002. Evaluating the effect of soft business support upon small firm performance. Oxford Economic Papers-New Series 54, 334-365.

Yafeh, Y., 2000. Corporate governance in Japan: past performance and future prospects. Oxford Review of Economic Policy 16, 74-84. 